\title{
SELECTION OF APPROPRIATE PROJECT MANAGEMENT METHODOLOGIES FOR EMERGENCY PROJECTS USING ANALYTIC HIERARCHY PROCESS
}

\begin{abstract}
This paper examines appropriate project management methodologies for use in emergencies. The use of appropriate project management methodologies is contingent to the successful execution of projects in terms of organization of project time, effective utilization of resources, minimization of project risk, cost/benefit relations and development of team skills. There are several project management methodologies, but a decisive factor in applying management methodologies is that they are not all suitable for all projects. Drawing on extant literature and expert opinion from leading project management organizations involved in emergencies and disaster management, this paper assesses a number of methodologies that have been deployed in emergency situations for delivery of projects. The Analytic Hierarchy Process, noted for its flexibility, systematic approach, robustness, and reproducible evaluation, is used to assess methodologies which can be used along the project life cycle and ranked in desirable order. The findings of this study are expected to be useful in improving current project management practices as well as relevant laws and regulations in times of emergencies. The study concludes that in terms of resources, using appropriate methodology helps shorten the project team's learning curve, allows teams to focus, ensures the project is free from the distractions caused by teams going off track or budget, empowers teams to deliver results that actually impact the business bottom line and contribute to the company's strategic goals. Finally, when the methodology is adapted with focus, it is possible to lower implementation risks and improve project delivery in emergencies.
\end{abstract}

Keywords: Agile, emergencies, project management methodologies, scrum traditional, waterfall.

\section{Introduction}

The frequency at which catastrophes and man-made disasters occur at global levels is alarming. The United Nations Disaster Risk Reduction (UNDRR-2020) reports that in the period between 2000 to 2019 , there have been as many as 7,348 major disaster events claiming 1.23 million lives, affecting 4.2 billion people (many on more than one occasion) resulting in approximately US\$2.97 trillion in global economic losses. The COVID-19 pandemic alone, as of October 2020, has claimed over 1.2 million lives (Johns Hopkins University- https://coronavirus.jhu.edu/) with trillions of financial impacts on the global economy. Disasters as referred in this paper include natural disasters like tsunami, hurricanes, earthquake, and man-made disasters ranging from planned terrorist attack, bush fires, power outages, chemical threat, biological threat, nuclear accidents, wars, explosion oil \& chemical spills, dam failure and of late the coronavirus pandemic.

When these disasters occur, responses involve a myriad of agencies, from government agencies at local, state, and federal level, to non-governmental and non-profit 
organizations, such as the Red Cross, as well as commercial entities contracted for the purpose of providing relief to help the deprived. Most emergency response efforts go into developing and repairing infrastructure projects in an attempt to mitigate the effect of the emergencies. In all instances, a coordinated effort is pivotal in identifying and prioritizing areas of dispossessions. This requires a whole life cycle of emergency management to identify areas of weaknesses. The major phases of such emergencies include prevention, preparedness, response, recovery, and mitigation. The role of government agencies at local, state, and federal levels in each phase needs to be analyzed. Prevention involves actions which reduce the potential for the occurrence of such incidents. Preparedness involves planning and identifying potential incident scenarios and training relevant personnel to effectively respond. By its nature of occurrence most often the action plan to mitigate emergencies are not coordinated well, or at best in a haphazard manner.

Using appropriate project management methodologies and management can potentially improve the delivery of such projects along the project life cycle. According to PMBOK (2017), project management is the application of knowledge, skills, tools, and techniques to project activities in order to meet project requirements. Project management is accomplished through initiating, defining, executing, monitoring, control and closing. Along the project life cycle, there are several/best practices of project management methodologies that can be utilized to successfully achieve the project objectives. The most popular ones are; Agile, Scrum, Kanban, Scrumban, Lean, eXtreme Programming (XP), Waterfall, PRINCE2 and PMI's PMBOK.

As to which type of project management methodology is suitable for emergency situations, there is no known research that has laid out such a methodology. Further, to many project managers, emergency situations are the least anticipated, resulting in a world of optimism until the unexpected happens. Then out of haste in an emergency situation, project managers rush to execute projects with whatever they have on hand. The question is, what project management methodologies are appropriate for emergency projects?

The aims of the research therefore is to assess the current project management methodologies used on projects, evaluate which elements are most suitable for project managers to allow for an adaptable methodology to manage projects in emergencies, understand any issues and challenges and seek potential solutions, examine whether organizations face similar issues and challenges which would be impacted by adaptable methodologies, and propose a framework to be applied to projects in case of emergency. Accordingly, the Analytic Hierarchy Process, noted for its flexibility, systematic approach, robustness, and reproducible evaluation is used to assess known methodologies used along the project life cycle and ranked in preferred order. The findings of this study are expected to be useful in improving current project management capability as well as impact relevant laws and regulations in formulation of contractual agreements.

\section{Literature Review}

Several papers have compiled Analytical Hierarchy Process (AHP) success stories in very different fields (Vargas, 1990); (Ho, 2008); (Golden, Wasil, Harker, \& Vargas, 1990); (Shim, 1989); (Saaty \& Forman, 1992); (Forman \& Gass, 2001); (Kumar \& Vaidya, 2006); (Omkarprasad, \& Sushil, 2006); (Liberatore \& Nydick, 2008); (Zahedi, 1986); Amponsah \& Adams, 2017). The oldest reference dates to 1972 (Saaty, 1972a), after this, (Saaty, 1977b), precisely described the method. The AHP technique developed by Thomas L. Saaty is aaMulti-Criteria Decision Analysis (MCDA) method that helps decision makers make the best decisions in the face of complex problems consisting of 
multiple conflicts and internal criteria. Project methodologies have been developed specifically to help address low success rates using project-related knowledge (The Standish Group, 2010; Wysocki, 2011).

When used for group decision making, MCDA helps facilitate talks about their decision opportunity (the problem to be solved) in a way that allows them to consider the values of each viewpoint. It also provides a unique ability for people to consider and talk about complex trade-offs among various alternatives. In effect, MCDA helps people think, re-think, query, adjust, decide, re-think further, test, adjust, and finally come to a decision. MCDA problems are comprised of five components: 1) Goal, 2) Decision maker or group of decision makers with opinions (preferences), 3) Decision alternatives, 4) Evaluation criteria (interests) 5) Outcomes or consequences associated with alternative/interest combination.

The PMI (2017) defines a project as a temporary endeavor undertaken to create a unique product, service or result. By extension, an emergency project is one that is emergent in nature and must be undertaken immediately to prevent or correct structural deficiencies or hazardous conditions that may harm or injure persons involved.

According to the PMBoK® Guide (PMI 2017, p. 5), PM is defined as 'the application of knowledge, skills, tools and techniques' to execute and deliver projects effectively and efficiently. This definition is applied to hard or tangible projects: 'hard issues and measures include time, cost and quality, traditional measures used to establish project success' (Crawford \& Pollack 2004, p. 2). Soft projects, on the other hand, mean intangible projects with a concern for the well-being of man and or the environment: 'community perception, safety, environmental impacts, legal acceptability, political and social impacts ... include benefits, stakeholders, value management, and communications' (ibid.).

Project management then is the application of knowledge, skills, tools, and techniques to project activities in order to meet project requirements; project management methodologies (PMM) are a set of guiding principles and processes for managing projects.

Literature is split on whether project methodologies directly contribute to the goals (Cooke-Davies \& Arzymanow, 2002; Fortune \& White, 2006; White \& Fortune, 2002 ) or to the perceived appropriateness of project management (Lehtonen \& Martinsuo, 2006). According to Wysocki (2011), every good project management methodology should be able to trace the estimated and actual task durations and where this may fall into the capabilities of project management software (PMS), rather than the PMM tool itself.

A PMM is essentially a set of guiding principles and processes for managing a project. The choice of methodology defines how work is done and communicated. So how should a project management methodology be chosen? The methodology chosen will depend on the team, project-type, and project-scope. Choosing PMMs is one of the first decisions that must be made as project managers. On paper, PMMs are an agnostic tool, i.e. one should be able to use any methodology regardless of what PM tool are used. In reality, most project management tools are specialized to use a handful of methodologies. This will be a deciding factor in what methodology to eventually choose for use in an emergency. Project management methodologies are classified in the main, Traditional (Waterfall) and Agile (Contemporary) way. The Traditional or Waterfall methodology is the oldest methodology and is at times called sequential. It was first outlined by Dr. Winston Royce in 1970 as a response to managing the increasingly complex nature of 
software development. Since then, it has become widely adopted, most prominently in the software industry. It is also heavily requirements-focused.

The Agile family of methodologies is opposite of the waterfall which emerged in response to the failure of the Waterfall method for managing complex projects. Although Agile PM ideas had been in use in the software industry for quite a while, it formally came into being in 2001 when several IT representatives released the "Agile Manifesto". In approach and ideology, as the name implies, the Agile method favors a fast and flexible approach (here is one way to understand Agile as explained to kids). There is no top-heavy requirements-gathering. Rather, it is iterative with small incremental changes that respond to changing requirements.

Despite the inherent potency of the various methodologies, practitioners are challenged in deploying the most appropriate one for any given scenario especially when it is needed spontaneously. Though there has been some work to categorize the methodologies, there are no known efforts to provide a vivid typology of the methodologies left alone to provide situations in which they can be applied (PMI, 2005). More importantly, in emergency situations, where there is no time to waste in response to project implementation, a well-defined and framed up approach is likely to lead to success. Thus practitioners and academics alike need a better understanding of project management methodologies in order to grasp the benefits, while avoiding potential pitfalls rather than in a trial and error approach.

\section{Objectives}

The objective of this study is to examine the appropriate project management methodology to be used for implementing projects in case of emergencies. Although there are well known and popular project management methodologies used across industries, this study seeks to assess the current project management methodologies used in emergency projects. This will help evaluate which elements of methodologies project managers found most essential as an adaptable and acceptable approach to manage projects in emergencies. It also seeks to understand issues and challenges specific to emergency projects and to present potential solutions for management, identify similar issues and challenges and assess how an adaptable methodology would be of impact, and propose a framework which can be applied to projects in case of emergency.

\section{Research Design/Methodology}

The study uses extant review of literature with the aim of determining the status of research on project management methodologies to identify their appropriateness for emergency work.

According to Simonovic (2011, p. 20), 'the nature of disasters and emergencies are changing and becoming more complex' This is due to the interaction of and changes in several systems, namely the environmental systems causing these changes, the humans and communities who live through these changes and the infrastructure which is affected by these changes. Due to the unknown consequences and uncertain impacts of a disaster event, there is a lack of control which puts any preparedness plans under 
extreme stress or renders them ineffective. Post-disaster projects, especially relief projects, are placed under equally extreme pressures due to the time factor, which is essential to the safety of the people affected.

The Analytic Hierarchy Process (AHP) a decision-aiding method developed by Saaty $(1980,1985 \& 1990)$ aims to quantify relative priorities for a given set of alternatives on a ratio scale, based on the judgment of the decision-maker while stressing the importance of the intuitive judgments of a decisionmaker as well as the consistency of the comparison of alternatives in the decision-making process. Since a decision-maker bases judgment on knowledge and experience and then makes decisions accordingly, the AHP approach agrees well with the behavior of a decision-maker. The strength of this approach is that it organizes tangible and intangible factors in a systematic way and provides a structured yet relatively simple solution to the decision-making problems (Skibniewski \& Chao 1992). In addition, by breaking a problem down in a logical fashion from the large, descending in gradual steps to the small, one is able to connect, through simple paired comparison judgments, the small to the large.

\section{Data/Model Analysis}

By following the AHP outline indicated above, the hierarchy of the problem can be developed for the project methodology as shown in Figure 1. The following can be done manually or automatically by using the Expert Choice software.

1. Synthesizing the pair-wise comparison matrix

2. Calculating the priority vector for a criterion such as technology

3. Calculating the consistency ratio

4. Calculating $\lambda \max$

5. Selecting appropriate values of the random consistency ratio from a table, and

6. Checking the consistency of the pair-wise comparison matrix to assess whether the decisionmakers' comparison was consistent or not.

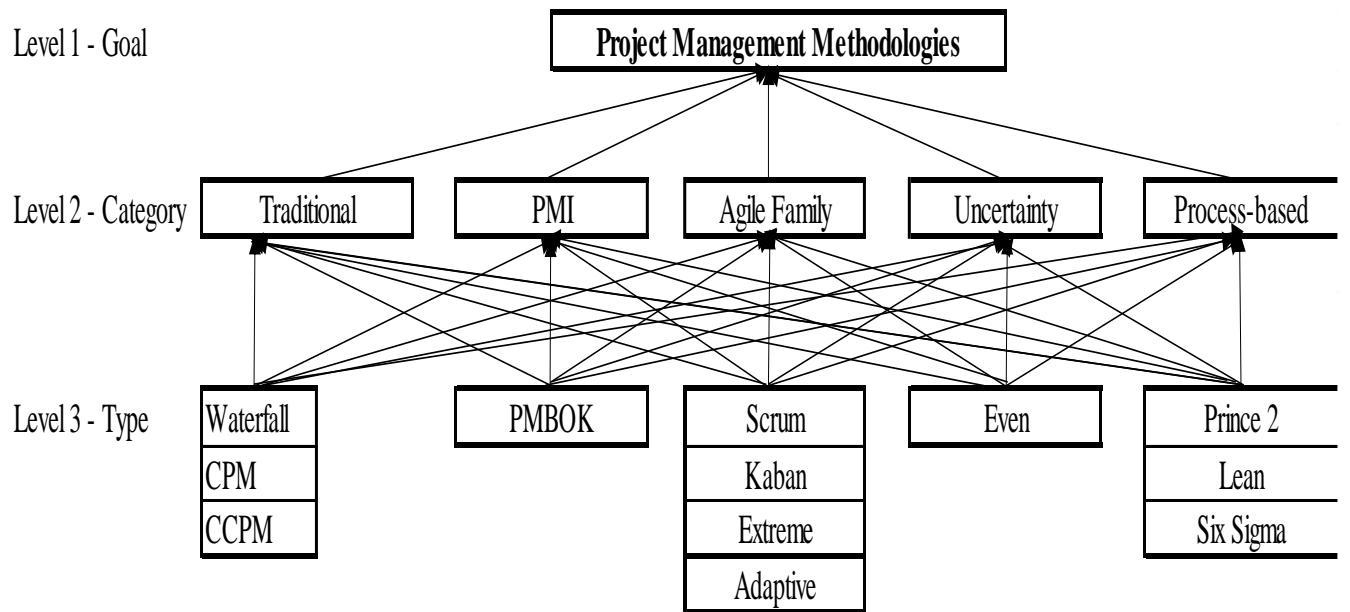

Figure 1: Hierarchy of Project Management Methodologies 
Selection of Appropriate Project Management Methodologies for Emergency Projects

Using Analytic Hierarchy Process. A paper submitted to the International Symposium of the

Analytic Hierarchy Process 2020, Web Conference.

\section{Limitations}

The present study is not without its limitations. The choice of search procedure meant total coverage of all the relevant empirical search on project methodology framework was not achieved. Papers may therefore have been included that did in fact address the project management methodology, but because of conceptual ambiguity, were not included. Yet, if the era of project management methodology really has started, then this procedure is certainly well justified. Finally, this paper proposes some research directions that are not exhaustive but rather represent the initial stages of a new line of inquiry. Further research can also be carried out with a larger sample across more organizations from different industries and regions in order to obtain more validated information that can be analyzed to draw conclusions on the various aspects and determinants of the project management methodology framework.

\section{Conclusions}

The AHP, noted for its flexibility, systematic approach, robustness, and reproducible evaluation, is used to assess how project management methodologies are used along the project life cycle and ranked in preferred order. The findings of this study are expected to be useful in improving current project management capability as well as relevant laws and regulations in times of emergency. The study concludes that in terms of resources, using appropriate methodology helps shorten the project team's learning curve, improves team focus, reduces distractions caused by teams going off track or budget, empowers teams to deliver results that actually impact the business bottom line and contributes to the company's strategic goals. Finally, when the methodology is adapted with focus, it is possible to lower implementation risks and improve project delivery in emergencies.

\section{References}

Amponsah, C.T., \& Adams S. (2017). Open innovation: systematisation of knowledge exploration and exploitation for commercialisation. International Journal of Innovation Management 21, (3) 1750027-1-26. DOI: 10.1142/S136391961 750027X

Cooke-Davies, T., \& Arzymanow, A. (2002). The "real" success factors on projects. International Journal of Project Management, 20(3), 471-478.

Forman, E., \& Gass, S. (2001) The Analytic Hierarchy Process, An Exposition. Operations Research, 49, 469-486.http://dx.doi.org/10.1287/opre.49.4.469.11231

Golden, B., Wasil, E, \& Harker, P., \& Vargas, L.G. (1990).The Analytic Hierarchy Process: Applications and Studies. Heidelberg, Springer-Verlag.

Ho, W. (2008). "Integrated analytic hierarchy process and its applications - A literature review." European Journal of Operational Research 186(1): 211-228

Lehtonen, P., \& Martinsuo, M. (2006). Three ways to fail in project management and the role of project management methodology. Project Perspectives, XXVIII, 6-11.

Liberatore, M., \& Nydick, R. (2008). The analytic hierarchy process in medical and health care decision making: A literature review. Eur. J. Oper. Res., 189, 194-207.

PMI, (2005). Project management methodology for post disaster reconstruction. Project Management Institute, Inc.

Project Management Institute/Agile Alliance ${ }^{\circledR}$ (2017). The agile practice guide. Newton Square, PA: Project Management Institute. 
Selection of Appropriate Project Management Methodologies for Emergency Projects

Using Analytic Hierarchy Process. A paper submitted to the International Symposium of the Analytic Hierarchy Process 2020, Web Conference.

Project Management Institute. (2017). A Guide to the project management body of knowledge (PMBOK® Guide) (6th ed.). Philadelphia, PA: Project Management Institute.

Saaty, T. (1972). An eigenvalue allocation model for prioritization and planning. Working paper, Energy Management and Policy Center, University of Pennsylvania.

Saaty, T.L. (1977b). "The Sudan transport study", Interfaces 20, 147-157.

Saaty, T.L. (1990). How to make a decision: the analytic hierarchy process. European Journal of Operational Research, North-Holland pg.48:9.

Saaty, T.L. (1985). Decision making for leaders. Belmont, California: Life Time Leaning Publications.

Saaty, T.L. (1980). The analytic hierarchy process. New York: McGraw- Hill,

Skibniewski, M.J., \& Chao, L. (1992) Evaluation of Advanced Construction Technology with AHP Method. Journal of Construction Engineering and Management, ASCE, 118, 577-593. http://dx.doi.org/10.1061/(ASCE)0733-9364(1992) 118:3(577)

Saaty, T., \& E. Forman (1992). The Hierarchon: A Dictionary of Hierarchies. Pittsburgh, RWS Publications.

Shim, J. (1989). "Bibliography research on the analytic hierarchy process (AHP)." Socio Economic Planning Sciences 23(3): 161-167.

Simonovic (2011, p. 20),

Vaidya, O. S., \& Kumar, S, (2006). "Analytic hierarchy process: An overview of applications," European Journal of Operational Research, Elsevier, vol. 169(1), pages 129, February.

Vargas, L. G. (1990). An overview of the Analytic Hierarchy Process and its applications, European Journal of Operational Research 48 (1990) pg. 2-8

White, D., \& Fortune, J. (2002). Current practice in project management-An empirical study. International Journal of Project Management, 20(1), 1-11.

Wysocki, R. K. (2014). Effective project management: Traditional, agile, extreme (8th ed.). Indianapolis, IN: John Wiley \& Sons, Inc.

Zahedi, F. (1986). "A simulation study of estimation methods in the analytic hierarchy process", Socio-Economic Planning Sciences 20, 347-354. 